\title{
Evaluation of factors determining pulmonary function in paediatric scoliosis
}

\author{
Amit Dwivedi ${ }^{1}$, Ashok Kumar ${ }^{2, *}$ \\ ${ }^{1}$ Assistant Professor, ${ }^{2}$ Professor, Dept. of Orthopedics, Santosh Medical College \& Hospital, Ghaziabad, Uttar Pradesh, India
}

Corresponding Author:

Email: kumarashokananddr@gmail.com

\begin{abstract}
Scoliosis affects approximately 7 million people in the United States. Infantile scoliosis is a rare entity, amounting for less than $1 \%$ of population.

Aims and Objectives: To evaluate the factors determining the pulmonary function tests in cases of idiopathic paediatric scoliosis.

Materials and Methods: The proposed study was conducted in the department of Orthopaedic Surgery, King George's Medical University Lucknow. The open ended study had been conducted on children having scoliosis in Paediateric age group and attending our outpatient department during August 2011 to July 2012. Detailed history and clinic-radiological examination was done. Total 33 patients were included in the study as per inclusion-exclusion criteria.

Results and Discussion: Clinic-radiological factors have an effect on pulmonary function test in scoliosis patients of paediatric age group. There is significant reduction in FVC and other parameters of PFT in Idiopathic scoliosis patients of paediatric age group.

Conclusion: Cardiopulmonary status of the patient is an important and vital parameter in the follow up of natural history of scoliosis, as it may affect the overall performance of the individual affected by this condition. Preoperative pulmonary function tests are essential to assess surgical risk in a patient with scoliosis because of the possibility of further compromising the pulmonary function.
\end{abstract}

Keywords: Idiopathicscoliosis, Pulmonary function test, Paediatric age, Cobb's angle, Cardiopulmonary Status.

\section{Introduction}

Scoliosis (from Greek: skoliōsis meaning from skolios, "crooked") is a medical condition in which a person's spine is curved from side to side. Although it is a complex three-dimensional deformity, on an X-ray, viewed from the rear, the spine of an individual with scoliosis may look more like an "S" or a "C" than a straight line. Scoliosis is defined as a curve of more than 10 degrees..$^{1-3}$

Scoliosis is typically classified as either congenital (caused by vertebral anomalies present at birth), idiopathic (cause unknown, sub-classified as infantile, juvenile, adolescent, or adult, according to when onset occurred), or neuromuscular (having developed as a secondary symptom of another condition, such as spina bifida, cerebral palsy, spinal muscular atrophy, or physical trauma). There are two types of scoliosis. Nonstructural (mobile) scoliosis is usually caused by a condition outside the spine and disappears when that is corrected. For example, if one of your legs is longer than the other, the curvature in your spine will disappear when you sit down. ${ }^{4}$

This condition affects approximately 7 million people in the United States. Infantile scoliosis is a rare entity, amounting for less than $1 \%$ of population. This condition is more common in Europe than in US. ${ }^{5}$

The infantile idiopathic scoliosis occurs before the age of 3 years and is seen more frequently in boys than girls. Most cases resolve spontaneously, but some may progress to more severe deformity. Juvenile idiopathic scoliosis is defined as scoliosis occurring between the age of 3 to 9 years. It is more frequent in girls. Adolescent idiopathic scoliosis occurs between ages of 10 years to young adult (18 years). This condition is by far the most common type of scoliosis, as well as the type with best prognosis. In general, the severity of the scoliosis depends on the degree of the curvature and whether it threatens vital organs, specifically the lungs and heart. ${ }^{4,5}$

Mild Scoliosis (less than 20 degrees), Moderate Scoliosis (between 25 and 70 degrees), Severe Scoliosis (over 70 degrees) and very severe scoliosis (Over 100 degrees).

Many adolescent girls who have scoliosis also have osteopenia. Some experts recommend measuring bone mineral density when a patient is diagnosed with scoliosis. The prognosis for a person with scoliosis depends on many factors, including the age at which scoliosis begins and the treatment received. Analysis of the efficacy of treatment in idiopathic scoliosis patients depends on understanding the natural history of the untreated condition and comparing it with the outcomes of treatment. Cardiopulmonary status of the patient is an important and vital parameter in the follow up of natural history of scoliosis, as it may affect the overall performance of the individual affected by this condition. It has been stated that preoperative pulmonary function tests are essential to assess surgical risk in a patient with scoliosis because of the possibility of further compromising the pulmonary function. ${ }^{6}$

Pulmonary function becomes limited as thoracic scoliosis becomes more severe ( 80 to 90 degree or more). Forced vital capacity (FVC) and forced 
expiratory volume in one second (FEV1) decrease linearly, with approximately a $20 \%$ reduction in predicted values in those with curves of 100 degree. The associated deformity of the chest cavity causes restrictive lung disease. Thoracic lordosis also decreases lung volume and increase the deleterious effect of scoliosis on pulmonary function. ${ }^{7-9}$

With this background the present study has been designed to evaluate the factors determining the pulmonary function tests in cases of idiopathic paediateric scoliosis. How do the standard clinicoradiological characteristics determine pulmonary functions are yet to be answered. This study will tend to answer it.

\section{Materials and Methods}

The proposed observational cross sectional study was conducted in the department of Orthopaedic Surgery, King George's Medical University Lucknow. The open ended prospective study had been conducted on children having scoliosis in Paediateric age group and attending our outpatient department during August 2011 to July 2012. Total 33 patients were included in the study as per inclusion-exclusion criteria. The five patients, in the age group of 2 to 6 years who were not able to perform spirometry were excluded from the study. So observation of only 28 children with idiopathic scoliosis were presented. Patients those are aged from 2 years to 16 years of both sexes, having idiopathic scoliosis and patients / attendants giving informed consent were included in the study. ${ }^{10}$ Patients who are aged $<2$ years and more than 16 years, having secondary scoliosis e.g. post-polio, limb length abnormality, associated neurofibromatosis etc., congenital scoliosis, associated Kyphosis / Lordosis, any significant systemic disease affecting lung functions and patients / attendants not giving informed consent were excluded from the study. ${ }^{11-13}$

All the patients included as per above inclusion/exclusion criteria had been subjected to the clinical evaluation using standardized pilot tested protocol to record comprehensively validly and precisely all features of patient demography, clinicoradiological characteristics of scoliosis which can determine pulmonary functions. Pulmonary function was tested at the department of physiology of this university. All the data had been recorded in the enclosed proforma.

The univariate association between characteristics of scoliosis and pulmonary function tests was determined. Those characteristics that are significantly associated with abnormal pulmonary functions in univariate analysis had been used together to develop a multivariate model to predict pulmonary functions. Predicted was validated against observed to determine the power of model to predict correctly. The residual errors had been analysed.
The data was entered in Microsoft Excel Sheet and checked for any inconsistency. The results are presented in percentages, mean $( \pm \mathrm{SD})$ and minimum maximum. The categorical/dichotomous variables are analysed by using Chi-Square/Fisher Exact Test. The two continuous variables are compared by using unpaired/paired t-test. More than two means are compared by using One Way Analysis of Variance (ANOVA). The p-value less than 0.05 is being considered significant. All the analysis is carried out by using SPSS 15.0 version.

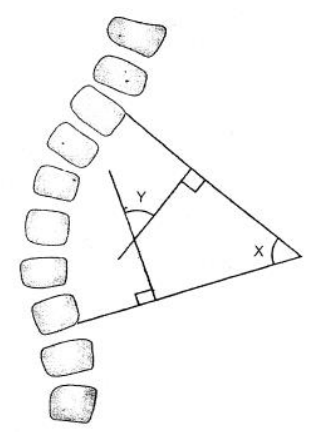

Fig. 1: Cobb's method of measuring severity of a curve $(Y=\text { angle })^{13}$

\section{Results and Discussion}

Total 33 patients were included in the study as per inclusion-exclusion criteria. The five patients, in the age group of 2 to 6 years who were not able to perform spirometry were excluded from the study. So observation of only 28 children with idiopathic scoliosis were presented.

Total 20 out of 28 patients i.e. $71.4 \%$ were between 10-16 years, 7 out of 28 patients i.e. $25 \%$ were between 6-10 years, and only one was in 2-6 years age i.e. $3.6 \%$. The (mean \pm SD) age of all the patients was 12.07 $( \pm 3.31)$. Majority of the males $(72.7 \%)$ and Females $(70.6 \%)$ patients were in age group 10-16 years. The difference in males and females was insignificant $(\mathrm{p}=0.71)$ in all age groups. (Table 1$)$

Table 1: Distribution of patients by age and sex

\begin{tabular}{|c|c|c|c|c|}
\hline \multirow{2}{*}{$\begin{array}{c}\text { Age in } \\
\text { years }\end{array}$} & \multicolumn{2}{|c|}{$\begin{array}{c}\text { Male } \\
(\mathbf{n = 1 1})\end{array}$} & \multicolumn{2}{c|}{$\begin{array}{c}\text { Female } \\
(\mathbf{n = 1 7})\end{array}$} \\
\cline { 2 - 5 } & No. & $\%$ & No. & $\%$ \\
\hline $02-6$ & 0 & 0.0 & 1 & 5.9 \\
\hline $6-10$ & 3 & 27.3 & 4 & 23.5 \\
\hline $10-16$ & 8 & 72.7 & 12 & 70.6 \\
\hline
\end{tabular}

Mean ( \pm SD) $12.07( \pm 3.31)$

Table 2 depicts the distribution of anthropometric parameters by age. The overall height (mean) was $138.04( \pm 20.17) \mathrm{cms}$ and (mean) weight was 32.07 $( \pm 10.17) \mathrm{kgs}$. There was increasing trend in height and weight as age increases. 
Table 2: Distribution of patients by anthropometric measurements

\begin{tabular}{|c|c|c|c|}
\hline Age in years & No. of patients & $\begin{array}{c}\text { Height in cms } \\
(\text { Mean } \pm \text { SD) }\end{array}$ & $\begin{array}{c}\text { Weight in Kg } \\
(\text { Mean } \pm \text { SD) }\end{array}$ \\
\hline $02-6$ & 1 & 108.00 & 15.00 \\
\hline $6-10$ & 7 & $118.00 \pm 12.50$ & $21.85 \pm 8.84$ \\
\hline $10-16$ & 20 & $146.55 \pm 16.04$ & $36.50 \pm 7.99$ \\
\hline Total & 28 & $138.04 \pm 20.17$ & $32.07 \pm 10.71$ \\
\hline
\end{tabular}

Values in the parenthesis are Min.-max.

Distribution of patients as per clinical parameters is given in the Table 3, Dorsolumbar curve was seen in 17 patients i.e. $60.7 \%$ of the patients. Rib hump towards right side was seen in 19 out of 28 cases i.e. $67.9 \%$ of the patients and similar observation was found for convexity of curve. Total 9 males out of total 11 males
(81.8\%) included, were having left Curve i.e. $81.8 \%$, while all females were having predominantly right curve. Clinical correct ability of curve was absent in all the patients. This observation ruled out any functional scoliosis.

Table 3: Distribution of patients as per clinical parameters

\begin{tabular}{|c|c|c|c|}
\hline S. No. & Parameters & $\begin{array}{c}\text { No. } \\
(\mathrm{n}=28)\end{array}$ & $\%$ \\
\hline \multirow{5}{*}{1} & \multicolumn{3}{|l|}{ Extent of scoliosis } \\
\hline & Dorso Cervical & 1 & 3.6 \\
\hline & Dorsal & 8 & 28.6 \\
\hline & Dorsolumbar & 17 & 60.7 \\
\hline & Lumbar & 2 & 7.1 \\
\hline \multirow{3}{*}{2} & \multicolumn{3}{|l|}{ Rib hump } \\
\hline & Left & 9 & 32.1 \\
\hline & Right & 19 & 67.9 \\
\hline \multirow{3}{*}{3} & \multicolumn{3}{|l|}{ Convexity of curv } \\
\hline & Left & 9 & 32.1 \\
\hline & Right & 19 & 67.9 \\
\hline \multirow{3}{*}{4} & \multicolumn{3}{|l|}{ Clinical correctability of curve } \\
\hline & Present & 0 & 0.0 \\
\hline & Absent & 28 & 100.0 \\
\hline
\end{tabular}

Distribution of patients as per radiological parameters studied was presented in the Table 4. Primary type of curve was predominant in all patients and dorsa lumbar as extent of curve was present in $60.7 \%$ of the patients. The right side convexity side was seen in $67.9 \%$ of the patients i.e. 19 out of 28 patients. The average Cobb's angle was $21.89( \pm 10.37)$ with range of minimum 15degrees and maximum of 42 degrees. More than $64 \%$ i.e. 18 out of 28 cases were in 10-20 degree Cobb's angle group (i.e. mild severity group). Iliac apophysis fusion (Reisser's Sign) was observed in this study. Total 9 cases $(32.1 \%)$ were in Reisser's grade 11, eight cases (28.6\%) in group I, 07 cases $(25 \%)$ in group III and rest $(14.3 \%)$ were in group IV. No. child was in group V.

Table 4: Distribution of patients as per radiological parameters

\begin{tabular}{|c|c|c|c|}
\hline S. No. & Parameters & No. $(n=28)$ & $\%$ \\
\hline \multirow{3}{*}{1} & Type of curve & & \\
\hline & Primary & 28 & 100.0 \\
\hline & Secondary & 0 & 0.0 \\
\hline \multirow{5}{*}{2} & Extent of curve & & \\
\hline & Dorsal cervical & 1 & 3.6 \\
\hline & Dorsal & 8 & 28.6 \\
\hline & Dorsal lumbar & 17 & 60.7 \\
\hline & Lumbar & 2 & 7.1 \\
\hline \multirow{3}{*}{3} & Convexity side & & \\
\hline & Left & 9 & 32.1 \\
\hline & Right & 19 & 67.9 \\
\hline
\end{tabular}




\begin{tabular}{|c|c|c|c|}
\hline \multirow{6}{*}{4} & \multicolumn{3}{|l|}{ Cobb's angle } \\
\hline & $10-20$ & 18 & 64.3 \\
\hline & $20-30$ & 4 & 14.3 \\
\hline & $30-40$ & 4 & 14.3 \\
\hline & $40-50$ & 2 & 7.1 \\
\hline & Mean \pm SD (Cob & 10. & rees) \\
\hline \multirow{6}{*}{5} & \multicolumn{3}{|c|}{ Iliac apophysis } \\
\hline & Grade I & 8 & 28.6 \\
\hline & Grade II & 9 & 32.1 \\
\hline & Grade III & 7 & 25.0 \\
\hline & Grade IV & 4 & 14.3 \\
\hline & Grade V & - & - \\
\hline
\end{tabular}

The distribution of pulmonary function test Spirometry is given in the Table 5. The average predicted FEVI was $2.06( \pm 0.52)$ and observed was $1.83( \pm 0.66)$ the $\%$ age observed predicated EFVI was $84.70( \pm 30.09)$. However, this was statistically insignificant $(p>0.05)$.

The average predicted FVC was $47.09( \pm 14.86)$ and observed was $56.65( \pm 24.62)$. The \%age observed predicted FVC was $47.09( \pm 14.79)$, and observed was 56.65 ( \pm 24.62 .) The \%age observed FVC was 89.85
$( \pm 14.79)$. However, this was statistically nearly significant $(\mathrm{p}=0.05)$.

The average predicted FEVI/FVC was 90.19 (+ 4.34) and observed was $89.96( \pm 9.26)$. The \%age observed predicted FEVI/FVC was $98.72( \pm 13.51)$. However, this was statistically insignificant $(\mathrm{p}>0.05)$.

The average predicted PEFR was $4.94(+1.33)$ and observed was $4.92( \pm 1.72)$. The \%age observed predicted PEFR was $88.34( \pm 37.12)$. However, this was statistically insignificant $(\mathrm{p}>0.05$.)

Table 5: Distribution of pulmonary function test-Spirometry

\begin{tabular}{|c|c|c|c|c|}
\hline & \multicolumn{4}{|c|}{ Pulmonary function test } \\
\hline & FEVI & FEVI/FVC & PEFR & FVC \\
\hline Predicted (Mean+SD) & $2.06 \pm 0.52$ & $90.19 \pm 4.34$ & $4.94 \pm 1.33$ & $47.09 \pm 14.86$ \\
\hline $\begin{array}{c}\text { Observed(Mean+SD) } \\
\text { \% observed predicted } \\
\text { (Mean+SD) }\end{array}$ & $1.83 \pm 0.66$ & $89.96 \pm 9.26$ & $4.92 \pm 1.72$ & $56.65 \pm 24.62$ \\
\hline $\begin{array}{c}\text { P-value (Predicted vs } \\
\text { Observed) }\end{array}$ & $04.70 \pm 30.0$ & $98.72 \pm 13.5$ & $88.34 \pm 37.8$ & $89.85 \pm 14.79$ \\
\hline \multicolumn{2}{|c|}{} & 0.92 & 0.97 & 0.05 \\
\hline
\end{tabular}

The comparison of clinical parameters with FEVI observed between predicted and observed FEVI level by clinical parameters. is given in the Table 6. No. significant association was

Table 6: Comparison of clinical parameters with FEVI

\begin{tabular}{|l|c|c|c|c|}
\hline Rib hump & $1.92 \pm 0.70$ & $1.47 \pm 0.48$ & $89.33 \pm 21.65$ & 0.23 \\
\hline Left (Mean+SD) & $2.09 \pm 0.47$ & $1.93 \pm 0.67$ & $83.43 \pm 32.31$ & 0.27 \\
\hline Right & 0.48 & 0.13 & 0.67 & \\
\hline P-value & - & - & - & - \\
\hline Clinical correctivity of curve & \multicolumn{5}{|l|}{} \\
\hline Present (Mean+SD) & NA & NA & NA & \\
\hline Absent (Mean+SD) & $2.05 \pm 0.52$ & $1.83 \pm 0.65$ & $84.69 \pm 30.08$ & 0.11 \\
\hline P-value & NA & &
\end{tabular}

The comparison of radiological parameters with FEVI/FVC is given in the Table 7. There was no significant difference between predicted and observed
FEVI/FVC and radiological parameters. However, there was significant difference $(p=0.04)$ among Cobb's angles in \%observed predicted.

Table 7: Comparison of radiological parameters with FEVI/FVC

\begin{tabular}{|c|c|c|c|c|}
\hline \multirow{2}{*}{$\begin{array}{c}\text { Radiological } \\
\text { Examination }\end{array}$} & Predicted & Observed & $\begin{array}{c}\text { \% Observed } \\
\text { predicted }\end{array}$ & p-value \\
\cline { 2 - 5 } & $90.19 \pm 4.39$ & $89.96 \pm 9.26$ & $98.71 \pm 13.51$ & 0.78 \\
\hline Type of Curve all & &
\end{tabular}




\begin{tabular}{|c|c|c|c|c|}
\hline $\begin{array}{l}\text { Primary } \\
(\text { Mean } \pm \text { SD) }\end{array}$ & & & & \\
\hline \multicolumn{5}{|l|}{ Extent of Curve } \\
\hline Dorsal cervical & $92.00 \pm 3.61$ & $79.00 \pm 18.52$ & $85.33 \pm 20.21$ & 0.29 \\
\hline Dorsal (Mean+SD) & $9.89 \pm 4.01$ & $88.51 \pm 6.42$ & $98.60 \pm 10.36$ & 0.67 \\
\hline $\begin{array}{l}\text { Dorsal Lumbar } \\
(\text { Mean } \pm \text { SD) }\end{array}$ & $89.85 \pm 4.69$ & $91.69 \pm 7.51$ & $100.12 \pm 12.76$ & 0.89 \\
\hline Lumbar (Mean+SD) & $88.74 \pm 6.03$ & $94.44 \pm 6.28$ & $106.50 \pm 14.85$ & 0.11 \\
\hline P-value & 0.83 & 0.14 & 0.29 & \\
\hline \multicolumn{5}{|l|}{ Convexity side } \\
\hline Left $($ Mean \pm SD) & $90.75 \pm 3.67$ & $90.43 \pm 5.60$ & $96.16 \pm 11.37$ & 0.98 \\
\hline Right (Mean+SD) & $90.03+4.62$ & $89.83+10.13$ & $99.41+14.19$ & 0.94 \\
\hline P-value & 0.73 & 0.89 & 0.61 & \\
\hline \multicolumn{5}{|l|}{ Cobb's angle } \\
\hline 10-20 ((Mean+SD) & $90.66 \pm 2.95$ & $87.27 \pm 10.07$ & $95.22 \pm 12.55$ & 0.56 \\
\hline 20-30 (Mean+SD) & $86.35 \pm 3.76$ & $95.34 \pm 6.95$ & $112.25 \pm 9.53$ & 0.34 \\
\hline $30-40($ Mean \pm SD $)$ & $91.24 \pm 8.82$ & $95.14+4.98$ & $105.02 \pm 14.69$ & 0.45 \\
\hline 40-50 (Mean+SD) & $91.50 \pm 4.94$ & $93.00 \pm 1.23$ & $90.50 \pm 9.19$ & 0.45 \\
\hline P-value & 0.31 & 0.23 & $0.04 *$ & \\
\hline \multicolumn{5}{|l|}{ Iliac apophysis } \\
\hline $\begin{array}{l}\text { Grade I } \\
(\text { Mean+SD) }\end{array}$ & $88.98 \pm 4.87$ & $93.43 \pm 4.89$ & $105.2 \pm 11.35$ & 0.34 \\
\hline $\begin{array}{l}\text { Grade II } \\
(\text { Mean } \pm \text { SD) }\end{array}$ & $90.60 \pm 3.12$ & $87.2 \pm 13.98$ & $93.66 \pm 16.70$ & 0.32 \\
\hline Grade III (Mean \pm SD) & $92.57 \pm 4.90$ & $85.53 \pm 2.90$ & $93.56 \pm 3.91$ & 0.54 \\
\hline $\begin{array}{l}\text { Grade IV } \\
(\text { Mean } \pm \text { SD) }\end{array}$ & $87.48 \pm 4.03$ & $96.95 \pm 3.50$ & $105.50 \pm 16.19$ & 0.45 \\
\hline Grade V & - & - & - & - \\
\hline $\mathrm{p}$-value & 0.23 & 0.11 & 0.16 & \\
\hline
\end{tabular}

\section{Conclusions}

Study concluded that clinic-radiological factors have an effect on pulmonary function test in scoliosis patients of paediatric age group. There is significant reduction in FVC and other parameters of PFT in Idiopathic scoliosis patients of paediatric age group. ${ }^{14,15}$

FVC tells about the restrictive lung disease and is the most significant parameter. Cardiopulmonary status of the patient is an important and vital parameter in the follow up of natural history of scoliosis, as it may affect the overall performance of the individual affected by this condition.

\section{Reference}

1. Weber B, Smith JP, Briscoe WA, Friedman SA, King TK. Pulmonary function in asymptomatic adolescents with idiopathic scoliosis. Ame Rev Resp Dis 1975;111(4):389-97.

2. Jackson et al. Plane Spinal Deformities Correlating with Back Pain and Pulmonary Function in Adult Idiopathic Scoliosis. Spine 1989;14:12.

3. Kearon C, Viviani GR, Kirkley A, Killian KJ. Factors determining pulmonary function in adolescent idiopathic thoracic scoliosis. Am Rev Respire Dis 1993;148(2):28894.

4. Kearon C, Viviani GR, Killian KJ. Factors influencing work capacity in adolescent idiopathic thoracic scoliosis. Am Rev Respire Dis 1993;148(2):295-303.
5. Upadhyay SS, Mullaji AB, Luk KD, Leong JC. Relation of spinal and thoracic cage deformities and their flexibilities with alteredpulmonary functions in adolescent idiopathic scoliosis. Spine 1995;20(22):241520.

6. Upadhyay SS, Mullaji AB, Luk KD, Leong JC. Evaluation of deformities and pulmonary function in adolescent idiopathic rightthoracic scoliosis. Euro Spine J 1995;4(5):274-9.

7. Vedantam, Ravishankar, Crawford, Alvin H. The Role of Preoperative Pulmonary Function Tests in Patients With Adolescent Idiopathic Scoliosis Undergoing Posterior Spinal Fusion. Spine 1997;22(23):2731-4.

8. Leong JC, Lu WW, Luk KD, Karlberg EM. Kinematics of the chest cage and spine during breathing in healthy individuals and inpatients with adolescent idiopathic scoliosis. Spine (Phila Pa) 1999;24(13):1310-5.

9. Newton Peter O. Faro Frances D. Gollogly Sohrab, Betz Randal R.Lenke et al. Results of preoperative pulmonary function testing of adolescents with idiopathic scoliosis: A study of six hundred and thirty-one patients. J Bon Joi Surg 2005;87A(9):1937-46.

10. Takahashi S, Suzuki N, Asazuma T, Kono K, Ono T, et.al. Factors of thoracic cage deformity that affect pulmonary function in adolescent idiopathic thoracic scoliosis. Spine (Phila Pa) 2007;32(1):106-12.

11. Newton PO, Perry A, Bastrom TP, Lenke LG, Betz RR, Clements D, et.al. Change in postoperative pulmonary function in adolescent idiopathic scoliosis: a prospective study of 254 patients. Spine (Phila Pa) 2007;32(17):1875-82. 
12. Karol LA, Johnston C, Mladenov Jackson, Roger P, Simons Edward H, Stripinis, Daniel Ma, et.al. Pulmonary function following early thoracic fusion in non-neuromuscular scoliosis. $J$ B $J S A m$ 2008;90(6):1272-81.

13. Yaszay; Burt MD, Jazayeri; Reza MD; Lonner, Baron MD. The effect of Surgical Approaches on Pulmonary function in Adolescent Idiopathic Scoliosis.J Spin Disor Techni 2009;22(4):278-83.

14. Lonner, Baron S, Auerbach, Joshua D, Estreicher, Michael B, Betz Randal R, Crawford Alvin H, Lenke, Lawrence G, et. al. Pulmonary Function Changes After
Various Anterior Approaches in the Treatment of Adolescent Idiopathic Scoliosis. J Spin Disor Techni 2009;22(8):551-8

15. Zhou C, Liu L, Song Y, Gong Q, Li T, Kong Q, Zeng J, Liu H. Pulmonary function changes after operation in patients with severe scoliosis. Zhongguo Xiи Fu Chong Jian Wai Ke Za Zhi 2010;24(1):23-6. 